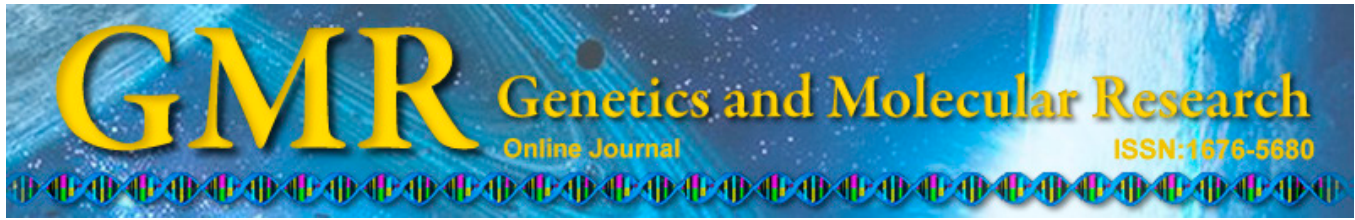

\title{
Association of polymorphism in ICAM-1 (K469E) and cytology parameters in patients' initial blood test with acute ischemic stroke
}

D. Wang' , F.H. Zhang', Y.T. Zhao ${ }^{3}$, X.G. Xiao' ${ }^{2}$ S. Liu' ${ }^{2}$ H.B. Shi',

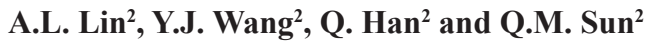

${ }^{1}$ Central Laboratory, Children's Hospital of Dalian, Dalian, China

${ }^{2}$ Clinical Laboratory, The First Affiliated Hospital of Dalian Medical University, Dalian, China

${ }^{3}$ Department of Laboratory Medicine, Jinzhou Central Hospital, Dalian, China

Corresponding author: F.H. Zhang

E-mail: zhangfenghua@sina.com

Genet. Mol. Res. 14 (4): 15520-15529 (2015)

Received August 6, 2015

Accepted October 9, 2015

Published December 1, 2015

DOI http://dx.doi.org/10.4238/2015.December.1.2

\begin{abstract}
Acute ischemic stroke (AIS) has become a serious health problem in many countries because of its poor outcome and worsening epidemic trend. Early identification of genetic risk factors and physiological indicators for stroke occurrence may help to reduce the incidence of stroke. Therefore, we conducted a case-control study including 50 AIS patients and 50 healthy individuals from a Chinese population to explore the association between AIS and patient complete blood profiles and the association between AIS and the genetic polymorphism $\mathrm{K} 469 \mathrm{E}$ in intercellular adhesion molecule-1 (ICAM-1). Compared to the control group, AIS patients showed a high percentage of mononuclear cells, low platelet count, low ratio of platelet to lymphocyte count, high frequency of the $469 \mathrm{~K}$ allele, and low frequency of the $469 \mathrm{E}$ allele. White blood cell count, percentage of neutrophils, percentage of lymphatic cells, platelet distribution width, mean platelet volume, and platelet hematocrit levels showed
\end{abstract}


no significant differences between the 2 groups and between different genotypes. Our results suggested an association of elevated levels of mononuclear cells and reduced platelet count with higher AIS risk. Our results also supported the hypothesis that the KK genotype at the $\mathrm{K} 469 \mathrm{E}$ locus in ICAM-1 is a risk factor for AIS.

Key words: Acute ischemic stroke; Complete blood count; K469E; Intercellular adhesion molecule-1; Mononuclear cells

\section{INTRODUCTION}

Acute ischemic stroke (AIS) is the most common form of stroke and accounts for $43-79 \%$ of the 2.5 million strokes each year, which includes 1.6 million fatal cases in China (Roach et al., 2008; Liu et al., 2011). More remarkably, current data indicate that a $50 \%$ increase in stroke incidence will occur in China over the next 20 years (Moran et al., 2010). Studies have shown that AIS results from genetic and environmental interactions (Mohr et al., 1997). Stroke risk may be related to age, gender, lifestyle, and many other disease conditions (Deb et al., 2010). Early identification of risk factors for stroke occurrence is important for reducing stroke incidence in medical practice. Complete blood count is one of the most common lab tests for many patients, which provides a comprehensive profile of red blood cells, leukocytes, and platelets. The role of platelet aggregation and activation in plaque formation, as well as the association between blood cell count and motility and recurrence of stroke have been reported in previous studies (Balestrino et al., 1998; Cherian et al., 2003; Kazmierski et al., 2004). Elevated white blood cell (WBC) count was reported to be associated with significantly higher mortality and poorer prognosis after AIS (Ganti et al., 2013; Furlan et al., 2014). A recent study in a Taiwanese population also showed a positive association between AIS risk and WBC and neutrophil count, suggesting that both counts may be useful for predicting longterm ischemic stroke events (Wu et al., 2013). However, the association between complete blood count results and AIS susceptibility has not been thoroughly investigated. Moreover, complete blood count data and AIS susceptibility may be affected by unique regional environmental factors, as dietary habits in a specific region may differ in different areas. For instance, people in Dalian, a coastal region, consume relatively large amounts of seafood, which likely affects AIS risk. Thus, association studies based on local populations may more accurately reflect local situations and be more valuable for local residents.

An increasing number of studies has reported multiple genetic factors that may modify the susceptibility to stroke (Morgan and Humphries, 2005; Cheng et al., 2008; Milton et al., 2011; Ma et al., 2013). These modifying genetic factors are associated with inflammation, lipid metabolism, and blood coagulation. Intercellular adhesion molecule-1 (ICAM-1) is an immunoglobulin superfamily member that plays an important role in inflammation. ICAM1 is widely expressed at low levels on the cell surface of mesenchymal cells in many tissues (Dustin et al., 1986; Seth et al., 1991). Substantially increased expression of endothelial ICAM-1 was observed in brain autopsies of patients who died from ischemic stroke, indicating an association between ICAM-1 expression and ischemic stroke (Lindsberg et al., 1996). Increased levels of soluble ICAM-1 were also reported to be associated with higher susceptibility to ischemic stroke (Tanne et al., 2002; Simundic et al., 2004). A genetic polymorphism in ICAM-1, K469E (rs5498), causes an amino acid change from glutamic acid (E) to lysine (K) 
in the ICAM-1 protein, resulting in changes in protein structure and immunoglobulin binding. Studies have shown that the K469E polymorphism in ICAM-1 may be associated with the susceptibility to multiple diseases such as inflammatory bowel disease, cardiovascular disease, and other related conditions (Matsuzawa et al., 2003; Nejentsev et al., 2003; Liu et al., 2004; Yang et al., 2004; Wei et al., 2005; Zhang et al., 2006; Li et al., 2009). Interestingly, a recent study from Li et al. (2009) reported that the 469E polymorphism was associated with higher stroke risk in females compared with $469 \mathrm{~K}$ in Chinese populations. However, whether the KK genotype or EE genotype at this locus is associated with higher stroke risk remains controversial, as discordant conclusions have been reported in different studies (Liu et al., 2004; Wei et al., 2005; Li et al., 2009).

To examine the association between the genetic polymorphism ICAM-1 K469E and complete blood count profiles in AIS patients from the Dalian area, we statistically analyzed complete blood count profiles and genotypes at the polymorphic locus, ICAM-1 K469E, in patients diagnosed with AIS and healthy individuals in a local Dalian hospital.

\section{MATERIAL AND METHODS}

\section{Study subjects}

Subjects were recruited from a Dalian area hospital and gender- and age-matched between groups to ensure that there was no statistically significant difference in demographic characteristics between the groups. The study conformed to the institutional ethical guidelines. The case group consisted of 50 patients, which included 27 males and 23 females aged 24-85 years who had been diagnosed with stroke by head magnetic resonance imaging and computed tomography scanning according to the China Diagnosis and Treatment Guidelines for Acute Ischemic Stroke (2010) in the First Hospital Affiliated with Dalian Medical University from September 2012 to December 2012. The mean age was $63.28 \pm 11.22$ years and $51.43 \pm$ 12.02 years for the case group and control group, respectively. All patients were free of other cardiovascular diseases, trauma, arterial inflammation, cancer, cerebral vascular malformation or aneurysm caused by secondary stroke, and recent drug interventions. The control group consisted of 50 healthy individuals, including 26 males and 24 females aged 23-81 years, who had undergone a routine health checkup during the same period in the same hospital and were healthy without history of stroke and other diseases involving the blood, liver, kidney, thyroid, autoimmune, and cerebrovascular systems.

\section{Methods}

\section{Sample collection}

Peripheral blood specimens were collected in tubes containing ethylenediaminetetraacetic acid as an anticoagulant from individuals after overnight fasting for subsequent analysis of complete blood counts and DNA analyses.

\section{DNA extraction and amplification}

Genomic DNA was extracted from blood samples using the GENERATION 
Capture Column Kit (Tiangen, Beijing, China) according to manufacturer instructions. Genomic DNA was stored at $-80^{\circ} \mathrm{C}$. DNA regions containing targeted single nucleotide polymorphisms (SNPs) were amplified using polymerase chain reaction (PCR) and specific primers designed and synthesized by TaKaRa Biotechnology (Dalian, China). The forward primer sequence was: 5'-AACCCATTGCCCGAGC-3'. The reverse primer sequence was: 5'-GGTGAGGATTGCATTAGGTC-3'. PCR conditions were: an initial incubation at $94^{\circ} \mathrm{C}$ for $1 \mathrm{~min}$, followed by 40 cycles of $94^{\circ} \mathrm{C}$ denaturation for $30 \mathrm{~s}, 55^{\circ} \mathrm{C}$ annealing for $30 \mathrm{~s}$, and $72^{\circ} \mathrm{C}$ extension for $30 \mathrm{~s}$. Final extension for PCRs was conducted by incubation at $72^{\circ} \mathrm{C}$ for $5 \mathrm{~min}$.

\section{Polymorphism analyzed by restriction enzyme digestion}

Enzyme digestion reactions were performed in a $20-\mu \mathrm{L}$ reaction system containing $12.5 \mu \mathrm{L}$ sterile distilled water, $5 \mu \mathrm{L}$ PCR products, $2 \mu \mathrm{L} \mathrm{10X} \mathrm{buffer,} \mathrm{and} 0.5 \mu \mathrm{L}$ Bst $\mathrm{UI}$ enzyme. The mixtures were incubated at $60^{\circ} \mathrm{C}$ for $4 \mathrm{~h}$. Digestion products were analyzed by electrophoresis $(1 \mathrm{~h}, 80 \mathrm{~mA})$ on a $3 \%$ agarose gel. Photographic images were acquired using the Gene Genius system (Syngene International, Karnataka, India) to analyze the genotypes of KK, EK, and EE.

\section{Polymorphism confirmation by sequencing}

PCR products from 10 randomly selected patients and 10 controls were purified and sequenced by TaKaRa Biotechnology. The sequencing results were compared to the enzyme digestion results to validate the genotype.

\section{Complete blood count}

WBC samples were loaded onto a Sysmex XE-5000 hematology analyzer (Sysmex Inc.; Kobe, Japan) to obtain blood profiles, which included WBC, neutrophil percentage (NEUT), lymphatic cell percentage (LYMPH), mononuclear cell percentage (MONO), platelet counts (PLT), platelet distribution width (PDW), mean platelet volume (MPV), and platelet hematocrit (PCT).

\section{Statistical analysis}

The SAS 9.2 software was used to perform statistical analyses (SAS Institute, Cary, $\mathrm{NC}$, USA). A two-factor design was used for analysis of variance. $\mathrm{P}<0.05$ was considered to indicate statistical significance.

\section{RESULTS}

\section{Complete blood count profiles for case and control groups}

Complete blood count profiles for both the patient and control groups are listed in Table 1. No statistically significant differences were observed in terms of $\mathrm{WBC}(\mathrm{F}=2.82, \mathrm{P}$ $>0.05)$, NEUT $(\mathrm{F}=1.83, \mathrm{P}>0.05)$, and LYMPH $(\mathrm{F}=0.54, \mathrm{P}>0.05)$. However, significant differences in MONO $(\mathrm{F}=10.52, \mathrm{P}<0.05)$ were observed between groups. The mean values 
for MONO were $7.76 \%$ and $6.14 \%$ for the patient and control group, respectively. Differences in PLT, PDW, MPV, and PCT were also not significant between the groups. However, the ratio of PLT/LYMPH ratio in the patient group (mean $=92.06)$ was significantly lower than that in the control group (mean $=119.18)(\mathrm{F}=5.09, \mathrm{P}<0.05)$. The ratio of NEUT to LYMPH did not show significant differences between groups $(\mathrm{F}=0.16, \mathrm{P}>0.05)$.

Table 1. Demographics and complete blood count characteristics in AIS patient and controls (Results are expressed as mean \pm standard deviation).

\begin{tabular}{|c|c|c|c|c|}
\hline & Patient group & Control group & $\mathrm{F}$ & $\mathrm{P}$ \\
\hline Number (male/female) & $50(27 / 23)$ & $50(26 / 24)$ & & \\
\hline Age (years) & $63.28 \pm 11.22$ & $51.43 \pm 12.02$ & 15.17 & 0.0002 \\
\hline $\mathrm{WBC}\left(10^{9} / \mathrm{L}\right)$ & $6.87 \pm 1.29$ & $6.19 \pm 1.01$ & 2.82 & 0.0962 \\
\hline NEUT (\%) & $55.06 \pm 7.39$ & $58.03 \pm 3.56$ & 1.83 & 0.1790 \\
\hline LYMPH (\%) & $34.32 \pm 7.10$ & $33.33 \pm 3.69$ & 0.54 & 0.4637 \\
\hline MONO (\%) & $7.67 \pm 1.37$ & $6.14 \pm 1.06$ & 10.52 & 0.0016 \\
\hline $\operatorname{PLT}\left(10^{9} / \mathrm{L}\right)$ & $213.61 \pm 50.48$ & $221.41 \pm 33.55$ & 4.35 & 0.0397 \\
\hline PDW [10 (GSD)] & $12.43 \pm 1.60$ & $12.08 \pm 1.18$ & 7.19 & 0.0087 \\
\hline MPV (fL) & $10.46 \pm 0.81$ & $10.23 \pm 0.62$ & 6.45 & 0.0128 \\
\hline PCT & $0.22 \pm 0.05$ & $0.23 \pm 0.03$ & 2.52 & 0.1160 \\
\hline PLT/LYMPH & $98.60 \pm 45.71$ & $115.07 \pm 34.68$ & 5.09 & 0.0263 \\
\hline NEUT/LYMPH & $1.74 \pm 0.83$ & $1.74 \pm 0.41$ & 0.16 & 0.6879 \\
\hline
\end{tabular}

\section{ICAM-1 genotypes in patient and control groups}

The 223-bp genomic region covering the SNP locus was amplified by PCR in all groups. Gel electrophoresis demonstrated that PCR products of unique sizes were generated (Figure 1a) and that no non-specific products were amplified.

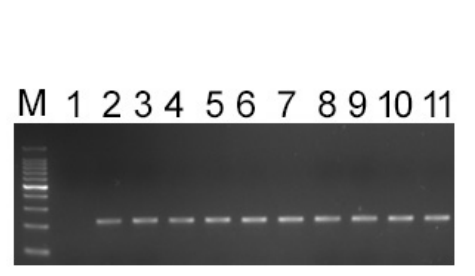

a

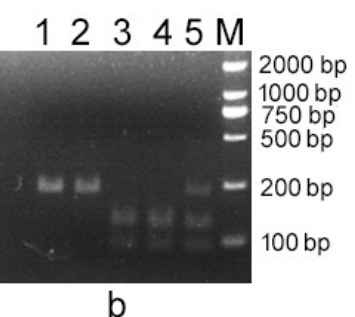

b

Figure 1. DNA analysis of products from PCR and enzyme digestion reactions. a. PCR products. Lane $M=100-\mathrm{bp}$ DNA ladder marker; lane $1=\mathrm{H}_{2} \mathrm{O}$; lanes 2-11= samples 1-10. b. Enzyme digestion products. Lane $M=2000$ bp DNA ladder marker; lanes 1 and 2 = two samples with KK genotype; lanes 3 and $4=$ two samples with EE genotype; lane 5 = a sample with EK genotype.

The K469E SNP in ICAM- 1 creates a new cleavage site for the restriction enzyme $B s t \mathrm{UI}$. Thus, the genotype of ICAM-1 at this locus can be defined based on fragment length patterns after Bst $\mathrm{UI}$ digestion (Figure 1b). Digestion of genotype KK samples gave rise to uncleaved DNA fragments of $223 \mathrm{bp}$, while the genotype EE gave rise to 2 cleaved fragments (136 and $87 \mathrm{bp}$ ) and the genotype EK gave rise to 3 fragments $(223,136$, and $87 \mathrm{bp}$ ). Representative examples corresponding to different genotypes are shown in Figure 1b. Genotype assays revealed that the numbers of individuals with the KK, EK, and EE genotypes in the 
patient groups were 41,4 , and 5 , respectively (Table 2 ). In the control group, the number of individuals per genotype group corresponded to 35,7 , and 8 , respectively (Table 2 ). The $\mathrm{K}$ and $\mathrm{E}$ allele frequencies in the patient group were 86 and 14\%, respectively (Table 2). The corresponding frequencies in the control group were 77 and 23\%, respectively (Table 2).

Table 2. Distribution of the different genotypes and allele frequencies.

\begin{tabular}{|c|c|c|c|c|c|c|}
\hline \multirow[t]{2}{*}{ Group } & \multirow[t]{2}{*}{ Total } & \multicolumn{3}{|c|}{$\mathrm{N}(\%)$} & \multicolumn{2}{|c|}{ Allele frequency (\%) } \\
\hline & & KK & EK & $\mathrm{EE}$ & $\mathrm{K}$ & $\mathrm{E}$ \\
\hline AIS & 50 & $41(82)$ & $4(8)$ & $5(10)$ & 86 & 14 \\
\hline Control & 50 & $35(70)$ & $7(14)$ & $8(16)$ & 77 & 23 \\
\hline
\end{tabular}

All genotypes were further validated in 10 randomly selected patients and 10 control samples by sequencing analyses. All sequencing results validated the enzyme digestion results for these samples. Representative examples of sequence results are shown in Figure 2.
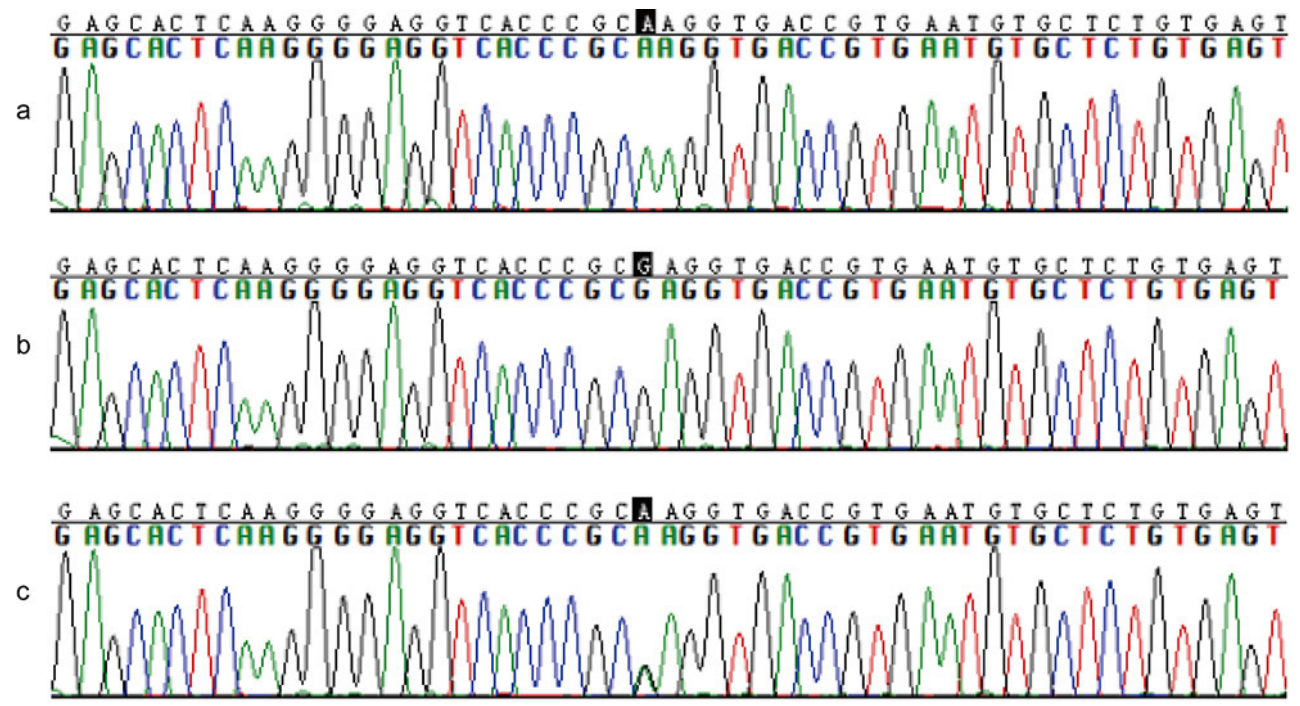

Figure 2. Sequencing analysis of patient pools. a. a sample with genotype KK (nucleotides = A/A); b. a sample with genotype $\mathrm{EE}$ (nucleotides $=\mathrm{G} / \mathrm{G}$ ); c. a sample with genotype $\mathrm{EK}$ (nucleotides $=\mathrm{G} / \mathrm{A}$ ).

\section{Association of WBC profiles and its subtypes with SNP K469E in both groups}

The WBC counts and the percentages of the WBC subtypes for the subgroups with different genotypes at K469E were further analyzed (Table 3). For the 3 genotype subgroups (KK, EK, and EE), we observed no statistically significant differences in $\mathrm{WBC}(\mathrm{F}=0.24, \mathrm{P}$ $>0.05)$, NEUT $(\mathrm{F}=1.27, \mathrm{P}>0.05)$, LYMPH $(\mathrm{F}=1.71, \mathrm{P}>0.05)$, and MONO $(\mathrm{F}=0.73, \mathrm{P}>$ $0.05)$ counts. There were also no significant interactions between disease condition (strokepositive or healthy) and genotype in terms of WBC $(\mathrm{F}=0.44, \mathrm{P}>0.05)$, NEUT $(\mathrm{F}=2.30, \mathrm{P}$ $>0.05)$, LYMPH $(\mathrm{F}=2.76, \mathrm{P}>0.05)$, and MONO $(\mathrm{F}=0.25, \mathrm{P}>0.05)$ counts. However, for genotype KK, there were significant differences $(\mathrm{F}=25.23, \mathrm{P}<0.0001)$ in MONO counts 
between the patient group (mean value $=7.82)$ and the control group (mean value $=6.08)$. For the genotypes EK $(\mathrm{F}=1.26, \mathrm{P}=0.2650)$ and $\mathrm{EE}(\mathrm{F}=3.01, \mathrm{P}=0.0861)$, these differences were not significant. For NEUT/LYMPH ratios, no significant differences between subgroups with different genotypes were observed $(\mathrm{F}=2.29, \mathrm{P}>0.05)$. However, a significant interaction between disease status and genotype on NEUT/LYMPH ratios was indicated $(\mathrm{F}=3.44$, $\mathrm{P}=0.0362$ ).

\begin{tabular}{|c|c|c|c|c|c|c|c|c|c|c|c|c|}
\hline \multirow[t]{2}{*}{ Group } & \multirow[t]{2}{*}{ GT } & \multirow[t]{2}{*}{$\mathrm{N}$} & \multicolumn{2}{|c|}{ WBC } & \multicolumn{2}{|c|}{ NEUT } & \multicolumn{2}{|c|}{ LYMPH } & \multicolumn{2}{|c|}{ MONO } & \multicolumn{2}{|c|}{ NEUT/LYMPH } \\
\hline & & & M & SD & M & SD & M & SD & M & SD & M & SD \\
\hline \multirow[t]{3}{*}{ AIS } & KK & 41 & 6.73 & 1.65 & 53.81 & 8.75 & 35.36 & 8.71 & 7.82 & 1.80 & 1.68 & 0.71 \\
\hline & EK & 4 & 6.30 & 1.00 & 50.20 & 10.46 & 41.75 & 12.80 & 7.18 & 0.43 & 1.33 & 0.57 \\
\hline & $\mathrm{EE}$ & 5 & 7.02 & 1.62 & 60.86 & 11.68 & 28.90 & 10.55 & 7.18 & 0.82 & 2.50 & 1.45 \\
\hline \multirow[t]{3}{*}{ Control } & KK & 35 & 6.21 & 1.36 & 57.35 & 4.74 & 34.27 & 4.79 & 6.08 & 1.24 & 1.73 & 0.42 \\
\hline & EK & 7 & 5.99 & 0.78 & 59.19 & 4.47 & 32.69 & 4.76 & 6.11 & 1.58 & 1.87 & 0.45 \\
\hline & $\mathrm{EE}$ & 8 & 5.73 & 0.88 & 56.96 & 4.38 & 34.35 & 3.83 & 5.69 & 1.36 & 1.69 & 0.35 \\
\hline
\end{tabular}

$\mathrm{GT}=$ genotype; $\mathrm{M}=$ mean; $\mathrm{SD}=$ standard deviation .

\section{Association of platelet profiles with disease condition and genotypes}

The association between platelet count-related cytology profiles and disease condition and genotypes was statistically analyzed (Table 4). A significant difference in platelet counts was observed between the patient and control groups $\left(213.61 \pm 0.48 \times 10^{9} / \mathrm{L}\right.$ for the case group and $221.41 \pm 33.55 \times 10^{9} / \mathrm{L}$ for the control group; $\left.\mathrm{F}=4.35, \mathrm{P}<0.05\right)$. The difference between different genotype groups was not significant $(\mathrm{F}=0.46, \mathrm{P}>0.05)$. There was also no significant interaction between disease condition (stroke-positive or healthy) and genotype regarding platelet counts $(\mathrm{F}=1.24, \mathrm{P}>0.05)$. Pairwise comparisons also revealed no significant difference regarding platelet count between genotype-specific patient and control subgroups.

\begin{tabular}{|c|c|c|c|c|c|c|c|c|c|c|}
\hline \multirow[t]{2}{*}{ Group } & \multirow[t]{2}{*}{ GT } & \multirow[t]{2}{*}{$\mathrm{N}$} & \multicolumn{2}{|c|}{ PLT } & \multicolumn{2}{|c|}{ PDW } & \multicolumn{2}{|c|}{ MPV } & \multicolumn{2}{|c|}{ PLT/LYMPH } \\
\hline & & & M & SD & $\mathrm{M}$ & $\overline{S D}$ & M & SD & M & SD \\
\hline \multirow[t]{3}{*}{ AIS } & KK & 41 & 216.88 & 65.00 & 12.32 & 1.85 & 10.42 & 0.90 & 100.83 & 49.18 \\
\hline & EK & 4 & 199.50 & 41.84 & 14.53 & 2.70 & 11.40 & 1.31 & 81.15 & 27.52 \\
\hline & EE & 5 & 179.00 & 47.69 & 12.70 & 2.27 & 10.56 & 1.14 & 94.19 & 21.44 \\
\hline \multirow[t]{3}{*}{ Control } & KK & 35 & 223.14 & 43.29 & 12.43 & 1.27 & 10.40 & 0.70 & 111.82 & 36.59 \\
\hline & EK & 7 & 240.86 & 50.48 & 11.49 & 1.30 & 9.96 & 0.67 & 126.08 & 35.20 \\
\hline & $\mathrm{EE}$ & 8 & 229.75 & 35.73 & 11.78 & 1.09 & 10.16 & 0.64 & 119.62 & 25.60 \\
\hline
\end{tabular}

$\mathrm{GT}=$ genotype; $\mathrm{M}=$ mean; $\mathrm{SD}=$ standard deviation.

Analyses of PDW data also revealed a significant difference in PDW between the patient and control groups $(\mathrm{F}=7.19, \mathrm{P}<0.05)$. Differences in PDW between genotype groups was also observed, but was not significant $(\mathrm{F}=0.75, \mathrm{P}>0.05)$. Our data revealed a significant interaction between disease status and genotype for PDW $(\mathrm{F}=4.36, \mathrm{P}<0.05)$. Moreover, stroke patients with the EK genotype had a significantly higher mean value of PDW compared to the control individuals with the EK genotype (14.53 vs 11.49, $\mathrm{F}=8.77, \mathrm{P}<0.05)$. No significant difference in PDW was observed between patients and controls with genotype KK (F 
$=0.08, \mathrm{P}=0.7721)$ or $\mathrm{EE}(\mathrm{F}=0.98, \mathrm{P}=0.3244)$. Within the patient group, patients with the KK genotype showed a higher mean value of PDW compared to patients with the EK genotype $(12.32$ vs $14.53, \mathrm{t}=2.567945, \mathrm{P}=0.0118)$.

Analyses of MPV data revealed a significant difference in MPV between the patient and control group $(\mathrm{F}=6.45, \mathrm{P}<0.05)$. MPV differences between subgroups with different genotypes were not significant $(\mathrm{F}=0.52, \mathrm{P}>0.05)$. We found a significant interaction between disease status and genotype for MPV $(\mathrm{F}=3.37, \mathrm{P}<0.05)$. Moreover, stroke patients with the EK genotype had a significantly higher mean value of MPV compared to control individuals with the EK genotype (11.40 vs 9.96, $\mathrm{F}=7.63, \mathrm{P}<0.05)$. No significant difference in MPV was observed between patients and controls with genotype KK $(\mathrm{F}=0.01, \mathrm{P}=0.9292)$ or $\mathrm{EE}$ $(\mathrm{F}=0.70, \mathrm{P}=0.4048)$. Patients with the KK genotype showed a lower mean value of MPV compared to patients with the EK genotype $(10.42 v s 11.40, t=2.251943, \mathrm{P}=0.0267)$.

For the PLT/LYMPH ratios, there were no significant differences between subgroups with different genotypes $(\mathrm{F}=0.02, \mathrm{P}>0.05)$. Interactions between disease status and genotypes for PLT/LYMPH ratios were also not significant $(\mathrm{F}=0.85, \mathrm{P}>0.05)$. Analyses of PCT data revealed no statistically significant differences (data not shown).

\section{DISCUSSION}

We analyzed the complete blood profiles and genotypes of ICAM- 1 K469E in AIS patients and healthy individuals and explored the association of K469E and AIS status with various blood parameters, including WBC count, percentages of WBC subtypes (NEUT, LYMPH, MONO, and NEUT/LYMPH), PLT count, and PLT-related references (PDW, MPV, PCT, and PLT/LYMPH). We identified associations of some of these blood parameters with the K469E polymorphism and AIS disease state.

In this study, the MONO percentage in the AIS patient group $(7.67 \pm 1.37 \%)$ was significantly higher than that in the control group (6.14 $\pm 1.06 \%$; Table 1$)$, suggesting an association between high MONO percentage and AIS occurrence. Similar differences in MONO levels were observed between AIS patients and control subjects with the KK genotype of ICAM-1 K469E (Table 3). Peripheral blood mononuclear cells, including macrophages, play essential roles in the immune system to fight infection. MONO cells also play crucial functions in inflammation reactions associated with stroke (Danton and Dietrich, 2003). It was previously reported that the number of MONO cells expressing interleukin-8 increased after stroke (Tuttolomondo et al., 2008). Elevated MONO cells may aggravate the stroke injury, and monitoring of MONO levels should be conducted for AIS follow-up (Lindsberg et al., 1996).

Both the PLT count and the PLT/LYMPH ratio in the AIS patient group were lower than these values in the control group (Table 1 and Table 4), suggesting an association between stroke occurrence and decreased PLT count. These are well-known common pathological features of stroke. The decreased free PLT count may be secondary to enhanced platelet activation and aggregation, which is commonly observed during stroke (Bigalke et al., 2012). However, the values of the PLT count and the PLT/LYMPH ratio did not appear to be associated with the ICAM-1 K469E locus. Inflammation is well known to play pivotal role in stroke (Danton and Dietrich, 2003; Tuttolomondo et al., 2008; Yamada et al., 2008). In addition to leukocytes and monocytes, the adhesion molecule ICAM-1 has been found to be closely associated with stroke occurrence (Lindsberg et al., 1996). As described above, it remains unclear whether the KK or EE genotype at the $\mathrm{K} 469 \mathrm{E}$ locus in ICAM-1 is a risk factor for stroke. Our 
results showed that the AIS patient group had a higher ratio of the KK genotype and lower ratio of the EE genotype compared to the healthy control group (Table 2), supporting previous conclusions that the genotype $\mathrm{KK}$ is associated with a higher risk of AIS occurrence.

It should be noted that our study population is small, limiting the statistical power analysis of our study. This may explain why we observed no associations between several other leukocytes and platelet profiles and AIS susceptibility and ICAM-1 polymorphism. Future studies including a larger sample size may provide additional insight.

In summary, we identified an association between elevated levels of mononuclear cells and decreased platelet count with AIS occurrence. Our results also support that the KK genotype at the K469E locus in ICAM-1 is a risk factor for AIS occurrence.

\section{Conflicts of interest}

The authors declare no conflict of interest.

\section{ACKNOWLEDGMENTS}

Research supported by the Liaoning Province Doctor Startup Fund (\#20111113). We thank Xiaolei Bao (Consulting Center of Biomedical Statistics in Academy of Military Medical Sciences at Beijing) for assistance with statistical analyses of data.

\section{REFERENCES}

Balestrino M, Partinico D, Finocchi C and Gandolfo C (1998). White blood cell count and erythrocyte sedimentation rate correlate with outcome in patients with acute ischemic stroke. J. Stroke Cerebrovasc. Dis. 7: 139-144.

Bigalke B, Schuster A, Sopova K, Wurster T, et al. (2012). Platelets in atherothrombosis - diagnostic and prognostic value of platelet activation in patients with atherosclerotic diseases. Curr. Vasc. Pharmacol. 10: 589-596.

Cheng J, Liu J, Li X, Yu L, et al. (2008). Effect of polymorphisms of endothelial nitric oxide synthase on ischemic stroke: a case-control study in a Chinese population. Clin. Chim. Acta 392: 46-51.

Cherian P, Hankey GJ, Eikelboom JW, Thom J, et al. (2003). Endothelial and platelet activation in acute ischemic stroke and its etiological subtypes. Stroke 34: 2132-2137.

Danton GH and Dietrich WD (2003). Inflammatory mechanisms after ischemia and stroke. J. Neuropathol. Exp. Neurol. 62: $127-136$

Deb P, Sharma S and Hassan KM (2010). Pathophysiologic mechanisms of acute ischemic stroke: An overview with emphasis on therapeutic significance beyond thrombolysis. Pathophysiology 17: 197-218.

Dustin ML, Rothlein R, Bhan AK, Dinarello CA, et al. (1986). Induction by IL 1 and interferon-gamma: tissue distribution, biochemistry, and function of a natural adherence molecule (ICAM-1). J. Immunol. 137: 245-254.

Furlan JC, Vergouwen MD, Fang J and Silver FL (2014). White blood cell count is an independent predictor of outcomes after acute ischaemic stroke. Eur. J. Neurol. 21: 215-222.

Ganti L, Gilmore RM, Weaver AL and Brown RD (2013). Prognostic value of complete blood count and electrolyte panel during emergency department evaluation for acute ischemic stroke. ISRN Stroke 2013: 1-5.

Kazmierski R, Guzik P, Ambrosius W, Ciesielska A, et al. (2004). Predictive value of white blood cell count on admission for in-hospital mortality in acute stroke patients. Clin. Neurol. Neurosurg. 107: 38-43.

Li XX, Liu JP, Cheng JQ, Han SH, et al. (2009). Intercellular adhesion molecule-1 gene K469E polymorphism and ischemic stroke: a case-control study in a Chinese population. Mol. Biol. Rep. 36: 1565-1571.

Lindsberg PJ, Carpen O, Paetau A, Karjalainen-Lindsberg ML, et al. (1996). Endothelial ICAM-1 expression associated with inflammatory cell response in human ischemic stroke. Circulation 94: 939-945.

Liu L, Wang D, Wong KS and Wang Y (2011). Stroke and stroke care in China: huge burden, significant workload, and a national priority. Stroke 42: 3651-3654.

Liu ZP, Huo Y, Li JP, Zhang Y, et al. (2004). Polymorphism K469E of intercellular adhesion molecule-1 gene and restenosis after coronary stenting in Chinese patients. Chin. Med. J. 117: 172-175. 
Ma S, He Z, Zhao J, Li L, et al. (2013). Association of AHSG gene polymorphisms with ischemic stroke in a Han Chinese population. Biochem. Genet. 51: 916-926.

Matsuzawa J, Sugimura K, Matsuda Y, Takazoe M, et al. (2003). Association between K469E allele of intercellular adhesion molecule 1 gene and inflammatory bowel disease in a Japanese population. Gut 52: 75-78.

Milton AG, Aykanat VM, Hamilton-Bruce MA, Nezic M, et al. (2011). Association of the phosphodiesterase 4D (PDE4D) gene and cardioembolic stroke in an Australian cohort. Int. J. Stroke 6: 480-486.

Mohr JP, Albers GW, Amarenco P, Babikian VL, et al. (1997). American Heart Association Prevention Conference. IV. Prevention and Rehabilitation of Stroke. Etiology of stroke. Stroke 28: 1501-1506.

Moran A, Gu D, Zhao D, Coxson P, et al. (2010). Future cardiovascular disease in China: Markov model and risk factor scenario projections from the coronary heart disease policy model - China. Circ. Cardiovasc. Qual. Outcomes 3: 243-252.

Morgan L and Humphries SE (2005). The genetics of stroke. Curr. Opin. Lipidol. 16: 193-199.

Nejentsev S, Laaksonen M, Tienari PJ, Fernandez O, et al. (2003). Intercellular adhesion molecule-1 K469E polymorphism: study of association with multiple sclerosis. Hum. Immunol. 64: 345-349.

Roach ES, Golomb MR, Adams R, Biller J, et al. (2008). Management of stroke in infants and children: a scientific statement from a Special Writing Group of the American Heart Association Stroke Council and the Council on Cardiovascular Disease in the Young. Stroke 39: 2644-2691.

Seth R, Raymond FD and Makgoba MW (1991). Circulating ICAM-1 isoforms: diagnostic prospects for inflammatory and immune disorders. Lancet 338: 83-84.

Simundic AM, Basic V, Topic E, Demarin V, et al. (2004). Soluble adhesion molecules in acute ischemic stroke. Clin. Invest. Med. 27: 86-92.

Tanne D, Haim M, Boyko V, Goldbourt U, et al. (2002). Soluble intercellular adhesion molecule-1 and risk of future ischemic stroke: a nested case-control study from the Bezafibrate Infarction Prevention (BIP) study cohort. Stroke 33: 2182-2186.

Tuttolomondo A, Di Raimondo D, di Sciacca R, Pinto A, et al. (2008). Inflammatory cytokines in acute ischemic stroke. Curr. Pharm. Des. 14: 3574-3589.

Wei YS, Liu YG, Huang RY, Tang RG, et al. (2005). Intercellular adhesion molecule-1 gene K469E polymorphism and genetic susceptibility of ischemic stroke in Chinese Zhuang populations. Zhonghua Yi Xue Yi Chuan Xue Za Zhi 22: 305-308.

Wu TH, Chien KL, Lin HJ, Hsu HC, et al. (2013). Total white blood cell count or neutrophil count predict ischemic stroke events among adult Taiwanese: report from a community-based cohort study. BMC Neurol. 13: 7.

Yamada Y, Ichihara S and Nishida T (2008). Proinflammatory gene polymorphisms and ischemic stroke. Curr. Pharm. Des. 14: 3590-3600.

Yang X, Cullen SN, Li JH, Chapman RW, et al. (2004). Susceptibility to primary sclerosing cholangitis is associated with polymorphisms of intercellular adhesion molecule-1. J. Hepatol. 40: 375-379.

Zhang SR, Xu LX, Gao QQ, Zhang HQ, et al. (2006). The correlation between ICAM-1 gene K469E polymorphism and coronary heart disease. Zhonghua Yi Xue Yi Chuan Xue Za Zhi 23: 205-207. 